\title{
Short- and long-term outcome after surgical aortic valve replacement in patients on dialysis
}

\author{
Sossio Perrotta ${ }^{1,2}$, Susanne J. Nielsen ${ }^{1,2}$, Emma C. Hansson ${ }^{1,2}$, Vincenzo Lepore ${ }^{1,2}$, Andreas Martinsson ${ }^{2,3}$, \\ Anders Jeppsson $^{1,2}$, Martin Lindgren ${ }^{2,4}$ \\ ${ }^{1}$ Department of Cardiothoracic Surgery, Sahlgrenska University Hospital, Gothenburg, Sweden; ${ }^{2}$ Department of Molecular and Clinical Medicine, \\ Institute of Medicine, Sahlgrenska Academy, University of Gothenburg, Gothenburg, Sweden; ${ }^{3}$ Department of Cardiology, Sahlgrenska University \\ Hospital, Gothenburg, Sweden; ${ }^{4}$ Department of Cardiology, Sahlgrenska University Hospital/Östra, Gothenburg, Sweden \\ Contributions: (I) Conception and design: S Perrotta, A Jeppsson, M Lindgren; (II) Administrative support: None; (III) Provision of study materials or \\ patients: None; (IV) Collection and assembly of data: None; (V) Data analysis and interpretation: S Perrotta, SJ Nielsen, EC Hansson, V Lepore, A \\ Jeppsson, M Lindgren; (VI) Manuscript writing: All authors; (VII) Final approval of manuscript: All authors \\ Correspondence to: Dr. Sossio Perrotta, MD, PhD. Department of Cardiothoracic Surgery, Sahlgrenska University Hospital, 41345 Gothenburg, \\ Sweden. Email: sossio.perrotta@vgregion.se.
}

Background: There is no consensus on the choice of aortic valve prosthesis for patients with end-stage renal failure. We analyzed short- and long-term complications in dialysis patients who underwent aortic valve replacement (AVR) with either a biological (bAVR) or a mechanical (mAVR) prosthesis.

Methods: All patients on dialysis who underwent bAVR or mAVR in Sweden from 1995 to 2017 ( $n=335)$ were included in a nationwide, population-based, observational, cohort study. Short and long-term complications were compared. Long-term mortality was compared with multivariable Cox regression analysis adjusted for age, sex, comorbidities, and a propensity score-matched model. Median follow-up was 2.8 (range, 0-16) years.

Results: Biological and mechanical valves were implanted in 253 (75.5\%) and 82 (24.5\%) patients, respectively. The bAVR patients were older and had more comorbidities. There was no significant difference in early complication rate. Thirty-day mortality was $9.1 \%$ in bAVR and $7.3 \%$ in mAVR patients $(\mathrm{P}=0.62)$. The multivariable Cox regression model did not show significant difference in mortality risk between bAVR and mAVR patients [adjusted hazard ratio (aHR) 1.33; 95\% CI: 0.84-2.13; P=0.22]. The results were confirmed in the propensity-score matched model. The rate of aortic valve reoperations did not differ significantly between the bAVR and mAVR group.

Conclusions: The short- and long-term complication rate is high, and the expected life expectancy limited, in dialysis patients undergoing AVR, without significant difference between biological and mechanical prostheses. The results suggest that biological valve prosthesis, avoiding systemic anticoagulation, is appropriate in most dialysis patients.

Keywords: Dialysis; aortic valve replacement (AVR); long-term outcome

Submitted Aug 25, 2021. Accepted for publication Dec 30, 2021.

doi: $10.21037 /$ jtd-21-1410

View this article at: https://dx.doi.org/10.21037/jtd-21-1410

\section{Introduction}

The prevalence of patients with end-stage renal disease requiring dialysis has increased over the past years from 741 per million population in year 2010 (1) to 897 per million in 2018 (2). The life expectancy for patients in dialysis is limited, in a recent study, the unadjusted 5 -year survival probability after the start of dialysis was $42.6 \%$ (2). Cardiovascular disease is the major cause of morbidity and mortality in dialysis patients and is present in $>50 \%$ of patients undergoing dialysis (3). A higher prevalence 
of aortic valve calcification and aortic stenosis with rapid progression has been observed in dialysis patients $(4,5)$.

It is still unclear which type of prosthesis is optimal for dialysis patients requiring aortic valve replacement (AVR). Initially, international guidelines recommended implantation of a mechanical valve in all dialysis-dependent patients, due to a perceived high risk of accelerated degeneration of biological prosthesis in dialysis patients, compromising the durability of the valve (6). More recent studies have reported that survival and reoperation rates in dialysis patients do not differ significantly between those treated with mechanical and those treated with biological valves (7-13). However, these studies are either single center studies (9-11) or include patients with different valve procedures in the same study cohort, e.g., both aortic and mitral valve replacements $(12,13)$. There is no previous nationwide study focusing on AVR in dialysis patients.

The aim of this population-based cohort study was therefore to analyze the association between the type of aortic valve prosthesis (biologic or mechanical) implanted and short- and long-term complications including mortality, in a comparatively large nationwide cohort of dialysis patients who underwent AVR with and without concomitant coronary artery bypass grafting (CABG). We present the following article in accordance with the STROBE reporting checklist (available at https://jtd.amegroups.com/article/ view/10.21037/jtd-21-1410/rc).

\section{Methods}

\section{Patients}

All 335 patients $\geq 18$ years with end stage renal disease and preoperative dialysis who underwent a first surgical implantation of a biological (bAVR) or a mechanical (mAVR) aortic valve prosthesis, isolated or in combination with CABG, from 1997 to 2017 in Sweden were included in a registry-based longitudinal cohort study. Patients with aortic valve endocarditis and those who underwent multiple valve implantation, homograft implantation, concomitant procedures other than $\mathrm{CABG}$ or had had previous aortic valve surgery were a priori excluded. The study was performed in compliance with the Declaration of Helsinki (as revised in 2013) and was approved by the regional Human Research Ethics Committee in Gothenburg, Sweden (approval number 139-16). The Ethics Committee waived the need for individual patient consent.

\section{Data sources and registered variables}

The study population was identified in the Swedish Cardiac Surgery Registry (14), which is a part of the SWEDEHEART Registry. The Cardiac Surgery Registry has collected information about patient characteristics, comorbidity including end-stage renal disease requiring dialysis, operative data, and early complications for all open-heart surgery procedures in Sweden since 1992. Reoperation for bleeding was defined as any reoperation for excessive postoperative bleeding and/or cardiac tamponade during the index hospital stay. "Postoperative heart failure" was defined as the need for inotropic support drugs for $>24$ hours or the use of an intra-aortic balloon pump or assist device. "Perioperative stroke" was defined as a new focal neurological deficit detected during the index hospitalization and lasting $>72$ hours. "Deep sternal wound infection" was defined as a deep infection requiring surgical debridement. "Aortic valve reoperation" was defined as any open aortic valve surgery procedure, or transcatheter aortic valve implantation (TAVI), registered in the Cardiac Surgery Registry or the National Patient Register during the follow-up period.

Additional information about comorbidities, not captured in the Swedish Cardiac Surgery Register, was collected from the National Patient Register. This register records the diagnoses from all hospital admissions in Sweden, and is considered complete after 1987 (15). The International Classification of Diseases (ICD), 9th and 10th revision (ICD-9 and ICD-10), was used to categorize comorbidities in the patient register (Table S1). Deaths beyond the immediate postoperative period were collected from the national Cause of Death Registry (16). Linkage between the registries was possible by using the unique personal identity number given to all Swedish citizens at birth or immediately after immigration (17).

\section{Statistical analysis}

Continuous data were reported as mean \pm standard deviation. For comparison between groups, Fisher's exact test was used for dichotomous variables and the MannWhitney $U$-test was used for continuous variables. Cumulative survival estimates were generated using the Kaplan-Meier method. Variables significantly associated with mortality in bivariate analysis were entered into a Cox multivariable analysis. In addition, sex and type of 
Table 1 Preoperative patient characteristics in 335 dialysis patients who underwent AVR with a biological or mechanical valve

\begin{tabular}{|c|c|c|c|c|}
\hline Variables & Total population $(\mathrm{n}=335)$ & Biological valve $(n=253)$ & Mechanical valve $(n=82)$ & $P$ value \\
\hline Male gender & $248(74.0)$ & $187(73.9)$ & $61(74.4)$ & 1.000 \\
\hline Age (years) & $67.1 \pm 10.5$ & $70.1 \pm 8.6$ & $57.8 \pm 10.3$ & $<0.001$ \\
\hline Body mass index & $27.0 \pm 5.2$ & $27.1 \pm 4.5$ & $26.8 \pm 7.0$ & 0.320 \\
\hline Previous myocardial infarction & $71(21.2)$ & $55(21.7)$ & $16(19.5)$ & 0.800 \\
\hline Previous stroke & $31(9.3)$ & $18(7.1)$ & $13(15.9)$ & 0.038 \\
\hline Diabetes & $114(34.0)$ & $91(36.0)$ & $23(28.0)$ & 0.240 \\
\hline Hypertension & 241 (71.9) & $192(75.9)$ & $49(59.8)$ & 0.008 \\
\hline Peripheral vascular disease & $73(21.8)$ & $60(23.7)$ & $13(15.9)$ & 0.170 \\
\hline History of cancer & $70(20.9)$ & $60(23.7)$ & $10(12.2)$ & 0.032 \\
\hline Hyperlipidemia & $69(20.6)$ & $59(23.3)$ & $10(12.2)$ & 0.038 \\
\hline
\end{tabular}

Data is presented as mean \pm standard deviation or numbers and percentages. AVR, aortic valve replacement; CABG, coronary artery bypass grafting.

prosthesis (biological or mechanical) were entered into the model. The Cox regression model was used to calculate hazard ratios (HRs) with $95 \%$ confidence intervals (CIs). The proportional hazard assumption was evaluated in an interaction model with the $\log$ of the survival time. The $\mathrm{P}$ value for the interaction between the log survival time and type of aortic valve was 0.82 , hence the proportional hazard assumption was fulfilled. Propensity score matching was performed using variables shown in Table 1. The matched groups were described by Kaplan-Meier curves stratified by type of aortic valve, and analyzed with log-rank test. The limited number of patients and events did not allow multivariate analysis of early mortality risk. A P value of $<0.05$ was considered statistically significant. All calculations were performed using version 9.4 of SAS (SAS Institute Inc., Cary, NC, USA).

\section{Results}

\section{Patients}

A total of 335 patients were included in the study. A flow chart over included and excluded patients is presented in supplementary Figure S1. Patient characteristics are presented in Table 1 and supplementary Table S2. Mean age was $67.1 \pm 10.5$ years and 248 patients $(74 \%)$ were men. Biological and mechanical valves were implanted in $253(75.5 \%)$ and 82 (24.5\%) patients, respectively. Six of the patients, four in the bAVR group (1.6\%) and two in the mAVR group (2.4\%), had a previous sternotomy. Seventy-five patients $(22.4 \%)$ had concomitant CABG. The patients in the bAVR valve group were older $(70.1 \pm 8.6$ vs. $57.8 \pm 10.3$ years, $\mathrm{P}<0.001)$ and had more comorbidities (stroke, history of cancer, diabetes, and hyperlipidemia) compared to the mAVR patients. The mean logistic EuroSCORE was $8.7 \% \pm 4.1 \%$ and $6.8 \% \pm 4.4 \%$, respectively, for the bAVR versus the mAVR group ( $\mathrm{P}=0.001)$. Median follow-up was 2.8 (range, $0-16$ ) years. No patient was lost to follow-up. During follow-up, a total of 26 patients, 16 in the bAVR group (6.3\%) and ten in the mAVR group (12.1\%), underwent kidney transplantation.

\section{Early outcome}

Twenty-nine out of 335 dialysis patients $(8.7 \%)$ died during the first 30 postoperative days, 24/260 (9.2\%) who had undergone isolated AVR and 5/75 (6.7\%) who had undergone AVR + CABG. Reoperation for bleeding occurred in $53 / 335(15.8 \%)$ of the patients, postoperative 
Table 2 Early complications in 335 dialysis patients who underwent AVR with a biological or mechanical valve

\begin{tabular}{|c|c|c|c|c|}
\hline Variables & Total population $(n=335)$ & Biological valve $(n=253)$ & Mechanical valve $(n=82)$ & $P$ value \\
\hline Reoperation for bleeding & $53(15.8)$ & $38(15.0)$ & $15(18.3)$ & 0.59 \\
\hline Postoperative heart failure & $44(13.1)$ & $34(13.4)$ & $10(12.2)$ & 0.94 \\
\hline Perioperative stroke & $36(10.7)$ & $29(11.5)$ & $7(8.5)$ & 0.61 \\
\hline
\end{tabular}

Data is presented as numbers and percentages. AVR, aortic valve replacement.

heart failure in $44 / 335(13.1 \%)$, perioperative stroke in $36 / 335$ (10.7\%), and deep sternal wound infection or mediastinitis in $14 / 335$ (4.2\%) of the patients (Table 2). Dialysis patients with combined aortic valve and CABG surgery had higher rates of postoperative heart failure, than patients with aortic valve surgery only (Table S3).

Neither 30 -day mortality $(9.1 \%$ vs. $7.3 \%, \mathrm{P}=0.62)$ nor the incidence of any other early complication differed significantly between the bAVR and mAVR groups, either in the total study population (Table 2), or in the propensity score-matched patients (Table S4).

\section{Long-term outcome}

\section{Mortality}

In total, 178 patients $(53.1 \%)$ died during follow-up (including early mortality), 136 (53.7\%) in the bAVR group and $42(51.2 \%)$ in the mAVR group. Cumulative survival in the whole patient population was $80 \%, 51 \%$, and $30 \%$ at 1,5 , and 10 years, respectively. The causes of death were cardiovascular in 104 cases (58.4\%), cancer in 14 (7.9\%), renal failure in $26(14.6 \%)$, sepsis in $13(7.3 \%)$, multi-organ failure in 11 (6.2\%), and "other" in 10 (5.6\%).

Age, diabetes, hypertension, heart failure, and history of cancer were significantly associated with total mortality in the bivariate analyses (Table 3). In the multivariable regression model, including variables that were significant according to the bivariate analysis, diabetes (adjusted hazard ratio (aHR) 1.60; 95\% CI 1.15-2.24, $\mathrm{P}=0.006$ ), heart failure (aHR 1.44; 95\% CI: 1.02-2.05; $\mathrm{P}=0.040$ ), and history of cancer (aHR 1.52; 95\% CI: 1.05-2.20; $\mathrm{P}=0.026$ ) were independently associated with total mortality (Table 3).

There was a significant difference in cumulative survival, with inferior unadjusted survival in patients with biological prostheses $(51 \%$ vs. $54 \%$ at 5 years, and $24 \%$ vs. $38 \%$ at 10 years, $\mathrm{P}=0.046$ ), Figure 1 . After adjustment, type of valve prosthesis was not associated with overall mortality risk (aHR 1.33; 95\% CI: 0.84-2.13; $\mathrm{P}=0.22$ ) (Table 3).

Propensity score matching yielded 70 patients in the biological valve group and 60 patients in the mechanical valve group. The groups were well balanced (Table S5). Long-term cumulative survival did not differ between propensity score-matched bAVR and mAVR patients (HR 1.05; 95\% CI: 0.65-1.69; log-rank test $\mathrm{P}=0.84$ ), Figure 2.

Cumulative survival did not differ significantly between AVR and AVR + CABG patients $(50 \%$ vs. $62 \%$ at 5 years and $29 \%$ vs. $31 \%$ at 10 years, $\mathrm{P}=0.55$ ), Figure 3. Concomitant CABG was not associated with higher overall mortality in the bivariate model (HR 0.89; 95\% CI: 0.61-1.30; $\mathrm{P}=0.55$ ).

Cumulative survival in relation to diabetes and heart failure is depicted in Figure 4. Patients with both diabetes and heart failure had an inferior cumulative survival compared to patients with neither of the conditions $(\mathrm{P}=0.001)$, and compared to those with heart failure only $(\mathrm{P}=0.009)$.

\section{Events during follow-up}

Number of events, events per 100 patient years, and unadjusted and aHRs for deaths, aortic valve reoperations major bleeding, ischemic strokes and myocardial infarction during follow-up are presented in Table 4. During followup, ten out of 335 patients $(2.1 \%)$ were reoperated on the aortic valve, $6 / 253(2.4 \%)$ in the bAVR group and $4 / 82$ $(4.9 \%)$ in the mAVR group. A Kaplan-Meier plot of the reoperations is presented in supplementary Figure S2. Three of the reoperations in the bAVR group were a TAVI. There were no significant differences in the adjusted risk for any of the reported events between the bAVR and mAVR group. 
Table 3 Bivariate and multivariable Cox regression analysis of potential predictors of long-term mortality in 335 dialysis patients who underwent AVR with a biological or mechanical valve

\begin{tabular}{|c|c|c|c|c|}
\hline Variables & \multicolumn{2}{|c|}{ Bivariate } & \multicolumn{2}{|c|}{ Multivariable } \\
\hline Type of aortic valve (biological vs. mechanical) & $1.08(0.72-1.61)$ & 0.720 & $1.33(0.84-2.13)$ & 0.220 \\
\hline Concomitant CABG & $0.89(0.61-1.30)$ & 0.550 & - & - \\
\hline Male gender & $1.32(0.96-1.83)$ & 0.092 & - & - \\
\hline Hypertension & $1.48(1.06-2.08)$ & 0.022 & - & - \\
\hline History of cancer & $1.52(1.08-2.14)$ & 0.017 & $1.52(1.05-2.20)$ & 0.026 \\
\hline Hyperlipidemia & $1.26(0.87-1.82)$ & 0.230 & - & - \\
\hline Peripheral vascular disease & $1.22(0.85-1.74)$ & 0.280 & - & - \\
\hline Heart failure & $1.76(1.30-2.37)$ & 0.001 & $1.44(1.02-2.05)$ & 0.040 \\
\hline Diabetes & $1.50(1.11-2.04)$ & 0.009 & $1.60(1.15-2.24)$ & 0.006 \\
\hline Previous stroke & $1.23(0.75-2.00)$ & 0.420 & - & - \\
\hline
\end{tabular}

Results are shown as HRs with 95\% Cls. *, adjusted for age, sex, and baseline comorbidities. AVR, aortic valve replacement; HR, hazard ratio; aHR, adjusted hazard ratio; $\mathrm{Cl}$, confidence interval; CABG, coronary artery bypass grafting.

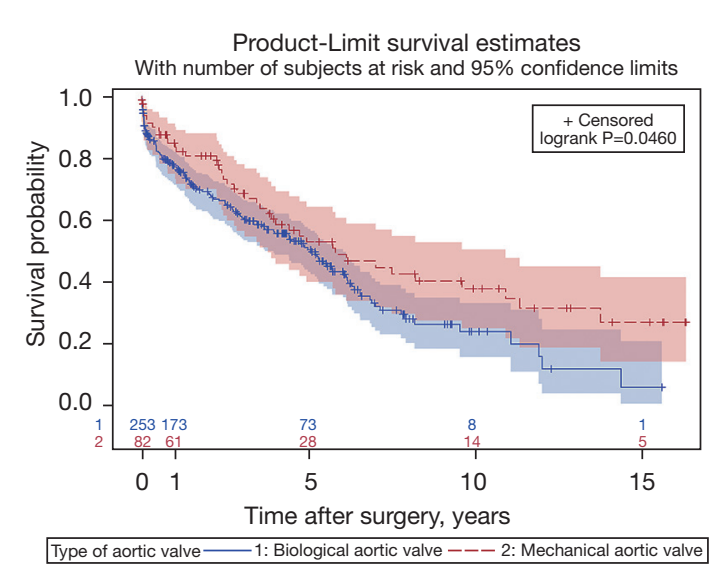

Figure 1 Cumulative survival plot for all patients stratified by type of aortic valve prosthesis [biological (blue curve) versus mechanical (red curve)]. There was a significant difference between the two groups (log-rank test $\mathrm{P}=0.046)$.

\section{Discussion}

The main findings of this population-based cohort study were: (I) the early and late complication rate in dialysis patients is high after AVR; (II) valve type was not associated

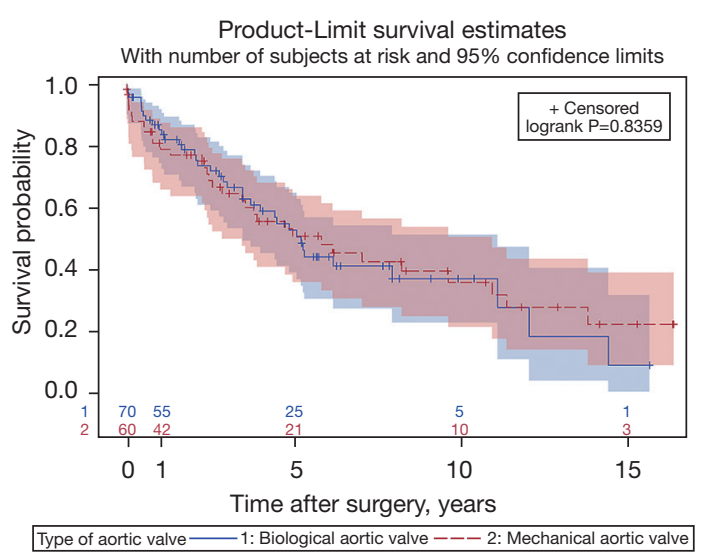

Figure 2 Cumulative survival plot showing the probability of death (95\% CIs), stratified by treatment group (the propensity score-matched biological versus mechanical group). There was no significant difference between the two groups (log-rank test $\mathrm{P}=0.84)$. CI, confidence interval.

with overall mortality risk after AVR in dialysis patients, either in multi-adjusted Cox regression analysis or after propensity score matching; (III) the incidence of aortic valve reoperation did not differ significantly between dialysis 


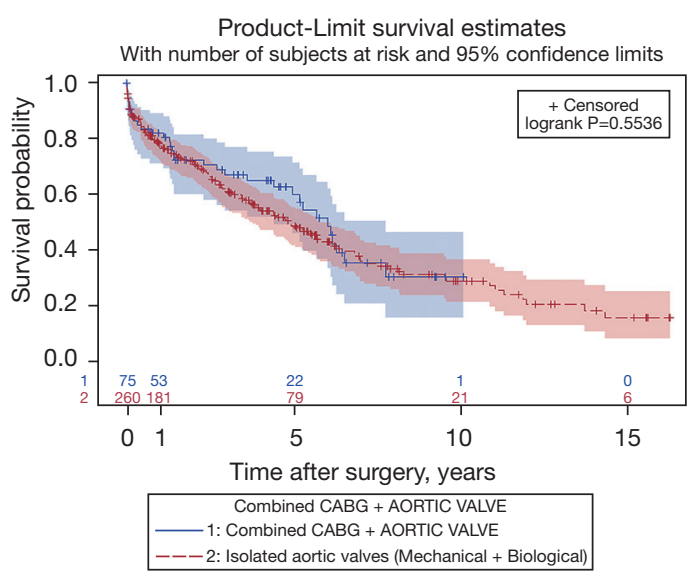

Figure 3 Kaplan-Meier plot for all patients stratified by treatment: AVR with concomitant CABG (blue curve) versus isolated AVR (red curve). There was no significant difference between the two groups (log-rank test $\mathrm{P}=0.55)$. AVR, aortic valve replacement; $\mathrm{CABG}$, coronary artery bypass grafting.

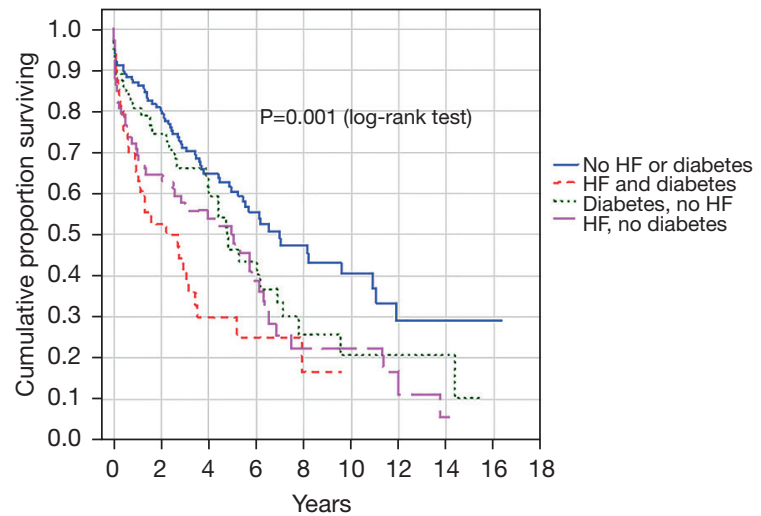

Figure 4 Cumulative survival in dialysis patients who underwent AVR, stratified by presence of diabetes and HF. Group 1: no diabetes and no HF ( $n=147)$; group 2: both diabetes and $\mathrm{HF}(\mathrm{n}=51)$; group 3: diabetes but no HF ( $n=64)$; group 4: HF but no diabetes $(\mathrm{n}=73)$. AVR, aortic valve replacement; HF, heart failure.

patients who received a biological, and dialysis patients who received a mechanical aortic prosthesis; and (IV) in unadjusted analysis, concomitant CABG was not associated with inferior survival in AVR patients on dialysis.

In the present study, the overall early complication rate and short- and long-term mortality was markedly higher in dialysis patients than has been reported in mixed AVR patient populations (18). This is in accordance with previous studies on the subject and can largely be explained by the high burden of risk factors in dialysis patients. For example, the prevalence of diabetes (34\%) and heart failure (37\%) and the mean logistic EuroSCORE are high in these patients compared to the CABG population. The outcome after implantation of biological or mechanical valve aortic prostheses in dialysis patients has been compared in a few studies $(9-13,19,20)$. Most of the previous studies in dialysis patients have been restricted by limited study populations, including patients from only one or a few centers (9-11), or patients with valves implanted in locations other than the aortic valve $(10,12,13)$.

Long-term mortality risk did, in the present study, not differ significantly between dialysis patients who received biological and mechanical prosthetic valves in the aortic location. These findings are in accordance with most contemporary studies $(9-11,13,19,20)$ and a systematic review (12). Hence, the present and previous studies, comparing mechanical versus biological valves in dialysis patients, have not shown a definitive advantage of one valve type.

In the present study, we observed a low overall rate of reoperation on the aortic valve $(2.1 \%$ or $0.81 \%$ per 100 patient years). The risk for reoperation was not higher in patients receiving a biological prosthesis than in those receiving a mechanical prosthesis, suggesting that few patients in the bAVR group developed structural valve deterioration requiring reoperation. In the present study, only $50 \%$ of the patients survived $>5$ years (Figure 1 ) and, hence, few biological prostheses may be needed to be replaced before patients succumb to their underlying diseases. Taken together with the lack of difference in long-term mortality between bAVR and mAVR, this indicates that a biological prosthesis, avoiding systemic anticoagulation, is an adequate choice in most patients with end-stage renal disease requiring dialysis.

Our results suggest however, that both biological and mechanical prostheses can be considered a valid alternative in dialysis patients. Several factors, such as the life expectancy, risks related to anticoagulation therapy, and the potential risk of early valve deterioration, should be considered when choosing the prosthesis that will be most suitable for the individual patient. In addition, the avoidance of systemic anticoagulation may have positive impact on the patients' quality of life. Furthermore, valve-in-valve TAVI can be used to treat structural valve deterioration in surgically implanted bioprostheses, allowing the use of biological valves in younger patients. In cases where dialysis patients are deemed to be candidates for future 
Table 4 Number of events, events per 100 patient years, and unadjusted and aHRs for deaths, aortic valve reoperations, major bleeding, ischemic strokes and myocardial infarction during follow-up in the bioprosthesis and mechanical prosthesis groups

\begin{tabular}{|c|c|c|c|c|c|c|c|c|}
\hline \multirow[t]{2}{*}{ Variables } & \multicolumn{2}{|c|}{$\begin{array}{c}\text { Number of events } \\
\text { (percentage) }\end{array}$} & \multicolumn{2}{|c|}{$\begin{array}{c}\text { Events per } 100 \text { patients years } \\
\text { with } 95 \% \mathrm{Cl}\end{array}$} & \multirow{2}{*}{$\begin{array}{c}\text { Un-aHR, bAVR } \\
\text { vs. mAVR with } \\
95 \% \mathrm{Cl}\end{array}$} & \multirow[t]{2}{*}{$P$ value } & \multirow{2}{*}{$\begin{array}{l}\text { aHR, bAVR vs. } \\
\text { mAVR with } 95 \% \mathrm{Cl}\end{array}$} & \multirow{2}{*}{$P$ value } \\
\hline & bAVR $(n=253)$ & $\mathrm{mAVR}(\mathrm{n}=82)$ & bAVR $(n=253)$ & mAVR $(n=82)$ & & & & \\
\hline Death & $136(53.7 \%)$ & $42(51.2 \%)$ & $16.3(13.7-19.3)$ & $10.6(7.6-14.3)$ & $1.08(0.72-1.61)$ & 0.72 & $1.33(0.84-2.13)^{\star}$ & 0.22 \\
\hline $\begin{array}{l}\text { Aortic valve } \\
\text { reoperation }\end{array}$ & $6(2.4 \%)$ & $4(4.9 \%)$ & $0.7(0.3-1.6)$ & $1.1(0.3-2.7)$ & $0.66(0.18-2.44)$ & 0.54 & - & - \\
\hline Ischemic stroke & $29(11.5 \%)$ & $9(11.0 \%)$ & $3.8(2.6-5.5)$ & $2.5(1.1-4.7)$ & $1.25(0.58-2.70)$ & 0.57 & $1.09(0.45-2.63)^{\#}$ & 0.84 \\
\hline Myocardial infarction & $25(9.9 \%)$ & $6(7.3 \%)$ & $3.2(2.1-4.7)$ & $1.6(0.6-3.5)$ & $1.61(0.66-4.00)$ & 0.29 & $1.52(0.54-4.17)^{\#}$ & 0.44 \\
\hline
\end{tabular}

*, adjusted for age, sex, gender, operation year, diabetes, hypertension, heart failure, history of cancer, previous myocardial infarction; **, adjusted for age, sex, gender, operation year, diabetes, heart failure; ", adjusted for age, sex, operation year. bAVR, biological aortic valve replacement; mAVR, mechanical aortic valve replacement; aHR, adjusted hazard ratio; $\mathrm{Cl}$, confidence interval.

kidney transplantation, the use of a mechanical valve may be considered because of the prolonged long-term survival after kidney transplant in patients with end-stage renal disease $(13,21)$.

The results of the present study suggest that the patient's comorbidities at the time of the operation are a major determinant of outcome. We observed that heart failure, diabetes, and history of cancer were independently associated with mortality during the follow-up period. Manghelli et al. estimated survival stratified both by age and by the presence of diabetes and/or heart failure in a mixed aortic and mitral valve replacement patient cohort (13). The authors reported that only young dialysis patients without diabetes and heart failure had a $>50 \%$ estimated 5 -year survival. This was largely confirmed in the present study where only patients without diabetes and/or heart failure had an expected life expectancy $>5$ years, Figure 4.

Concomitant CABG was not significantly associated with inferior unadjusted survival in the present study. The preoperative characteristics of this group of patients did not differ much compared to the group of patients undergone isolated AVR (Table S2). This suggests that the presence of coronary artery disease is less decisive for longterm survival than the renal disease per se and also than other comorbid conditions, including heart failure. The present result is at odds with the smaller studies of Fukui et al. and Horst et al., who found that concomitant CABG was associated with inferior long-term survival $(11,22)$. The difference between these results and ours may be explained by discrepant characteristics between the study cohorts. The cohort of patients in our study was markedly larger and enrolled in more recent years compared to the ones in Fukui et al. and Horst et al. $(11,22)$.

The present study has both strengths and limitations. Strengths include the comparatively large nationwide study population, consisting only of AVR patients, with and without concomitant CABG. Furthermore, data was collected from validated registries and databases and none of the patients were lost to follow-up. Limitations include the ones inherent in retrospective observational studies, such as selection bias and unregistered confounders. Lack of access to any echocardiographic follow-up limits the more detailed study of structural valve deterioration in the biological valve group. However, reoperations in the bAVR group were sparse, only $2.4 \%$ of the patients underwent reoperations with either surgical aortic valve replacement (SAVR) or TAVI during the limited follow-up period. This argues against that severe structural valve deterioration (SVD), necessitating reoperation, occurs early after bAVR in dialysis patients. Numerically, reoperations were in fact more common in mAVR patients (4.9\%). Furthermore, improvements of valve prostheses over the years may impact the results.

In conclusion, most patients on dialysis requiring implantation of biological or mechanical aortic valve prosthesis have limited long-term survival. There is no significant difference in the adjusted survival and freedom from reoperation between dialysis patients receiving a biological prosthesis and dialysis patients receiving a mechanical prosthesis. The results suggest that a biological prosthesis, avoiding systemic anticoagulation, is an adequate choice in most patients with end-stage renal disease requiring dialysis. 


\section{Acknowledgments}

Funding: This study was supported by the Swedish HeartLung Foundation (Grant No. 20180560 to AJ); the Swedish State (Grant No. ALFGBG-725131 to AJ) under the ALF agreement between the Swedish government and the county councils concerning economic support of research and education of doctors; Region Västra Götaland (Grant No. VGFOUREG-847811 to AJ); and Family Nils Winberg's Foundation. The supporting bodies had no influence on the analysis and interpretation of data, on the writing of the report, or on the decision to submit the paper for publication.

\section{Footnote}

Reporting Checklist: The authors have completed the STROBE reporting checklist. Available at https://jtd. amegroups.com/article/view/10.21037/jtd-21-1410/rc

Data Sharing Statement: Available at https://jtd.amegroups. com/article/view/10.21037/jtd-21-1410/dss

Peer Review File: Available at https://jtd.amegroups.com/ article/view/10.21037/jtd-21-1410/prf

Conflicts of Interest: All authors have completed the ICMJE uniform disclosure form (available at https://jtd.amegroups. com/article/view/10.21037/jtd-21-1410/coif). AJ reports personal fees from Boehringer-Ingelheim, Werfen, Alexion, Baxter, and LFB Biomedicaments, research grants from Swedish state, Swedish Heart Lung Foundation, Västra Götaland Region and Winberg Foundation, and he was a member of the Clinical Guideline Committee for the European Association for Cardiothoracic Surgery, outside the submitted work. ECH reports personal fees from AstraZeneca and Boehringer-Ingelheim, outside the submitted work. The other authors have no conflicts of interest to declare.

Ethical Statement: The authors are accountable for all aspects of the work in ensuring that questions related to the accuracy or integrity of any part of the work are appropriately investigated and resolved. The study was conducted in accordance with the Declaration of Helsinki (as revised in 2013). The study was approved by the regional Human Research Ethics Committee in Gothenburg, Sweden (approval number 139-16). The Ethics Committee waived the need for individual patient consent.

Open Access Statement: This is an Open Access article distributed in accordance with the Creative Commons Attribution-NonCommercial-NoDerivs 4.0 International License (CC BY-NC-ND 4.0), which permits the noncommercial replication and distribution of the article with the strict proviso that no changes or edits are made and the original work is properly cited (including links to both the formal publication through the relevant DOI and the license). See: https://creativecommons.org/licenses/by-nc-nd/4.0/.

\section{References}

1. Kramer A, Stel VS, Abad Diez JM, et al. Renal replacement therapy in Europe-a summary of the 2010 ERA-EDTA Registry Annual Report. Clin Kidney J 2013;6:105-15.

2. Kramer A, Boenink R, Stel VS, et al. The ERA-EDTA Registry Annual Report 2018: a summary. Clin Kidney J 2020;14:107-23.

3. Cozzolino M, Mangano M, Stucchi A, et al. Cardiovascular disease in dialysis patients. Nephrol Dial Transplant 2018;33:iii28-34.

4. Kim D, Shim CY, Hong GR, et al. Effect of End-Stage Renal Disease on Rate of Progression of Aortic Stenosis. Am J Cardiol 2016;117:1972-7.

5. Samad Z, Sivak JA, Phelan M, et al. Prevalence and Outcomes of Left-Sided Valvular Heart Disease Associated With Chronic Kidney Disease. J Am Heart Assoc 2017;6:006044.

6. Bonow RO, Carabello B, de Leon AC Jr, et al. Guidelines for the management of patients with valvular heart disease: executive summary. A report of the American College of Cardiology/American Heart Association Task Force on Practice Guidelines (Committee on Management of Patients with Valvular Heart Disease). Circulation 1998;98:1949-84.

7. Nishimura RA, Otto CM, Bonow RO, et al. 2014 AHA/ ACC Guideline for the Management of Patients With Valvular Heart Disease: executive summary: a report of the American College of Cardiology/American Heart Association Task Force on Practice Guidelines. Circulation 2014;129:2440-92.

8. Falk V, Baumgartner H, Bax JJ, et al. 2017 ESC/EACTS Guidelines for the management of valvular heart disease. Eur J Cardiothorac Surg 2017;52:616-64.

9. Okada N, Tajima K, Takami Y, et al. Valve selection for 
the aortic position in dialysis patients. Ann Thorac Surg 2015;99:1524-31.

10. Zhibing Q, Xin C, Ming X, et al. Should bioprostheses be considered the valve of choice for dialysis-dependent patients? J Cardiothorac Surg 2013;8:42.

11. Fukui S, Yamamura M, Mitsuno M, et al. Aortic valve prosthesis selection in dialysis patients based on the patient's condition. J Artif Organs 2012;15:162-7.

12. Phan K, Zhao DF, Zhou JJ, et al. Bioprosthetic versus mechanical prostheses for valve replacement in end-stage renal disease patients: systematic review and meta-analysis. J Thorac Dis 2016;8:769-77.

13. Manghelli JL, Carter DI, Khiabani AJ, et al. A 20-year multicenter analysis of dialysis-dependent patients who had aortic or mitral valve replacement: Implications for valve selection. J Thorac Cardiovasc Surg 2019;158:805813.e2.

14. Vikholm P, Ivert T, Nilsson J, et al. Validity of the Swedish Cardiac Surgery Registry. Interact Cardiovasc Thorac Surg 2018;27:67-74.

15. Ludvigsson JF, Andersson E, Ekbom A, et al. External review and validation of the Swedish national inpatient register. BMC Public Health 2011;11:450.

Cite this article as: Perrotta S, Nielsen SJ, Hansson EC, Lepore V, Martinsson A, Jeppsson A, Lindgren M. Short- and long-term outcome after surgical aortic valve replacement in patients on dialysis. J Thorac Dis 2022;14(2):269-277. doi: $10.21037 /$ jtd-21-1410
16. Brooke HL, Talbäck M, Hörnblad J, et al. The Swedish cause of death register. Eur J Epidemiol 2017;32:765-73.

17. Ludvigsson JF, Almqvist C, Bonamy AK, et al. Registers of the Swedish total population and their use in medical research. Eur J Epidemiol 2016;31:125-36.

18. Spadaccio C, Alkhamees K, Al-Attar N. Recent advances in aortic valve replacement. F1000Res 2019;8:eF1000 Faculty Rev-1159.

19. Ikeno Y, Mukohara N, Fukumura Y, et al. Outcomes of valve replacement with mechanical prosthesis versus bioprosthesis in dialysis patients: A 16-year multicenter experience. J Thorac Cardiovasc Surg 2019;158:48-56.e4.

20. Nakatsu T, Minakata K, Tanaka S, et al. Intermediate-term outcomes of aortic valve replacement with bioprosthetic or mechanical valves in patients on hemodialysis. J Thorac Cardiovasc Surg 2019;157:2177-2186.e3.

21. Williams ML, Bavaria JE, Acker MA, et al. Valve Selection in End-Stage Renal Disease: Should It Always Be Biological? Ann Thorac Surg 2016;102:1531-5.

22. Horst M, Mehlhorn U, Hoerstrup SP, et al. Cardiac surgery in patients with end-stage renal disease: 10-year experience. Ann Thorac Surg 2000;69:96-101. 
Supplementary

Table S1 ICD codes used for defining comorbidities

\begin{tabular}{lcc}
\hline Baseline comorbidities & ICD-9 & ICD-10 \\
\hline Ischaemic stroke & 434,436 & I63, I64 \\
Diabetes & $250-E 14$ \\
Hypertension & $401-405$ & I10-I15 \\
Heart failure & 425,428 & I42, I43, I50 \\
Atrial fibrillation & $427 D$ & I48 \\
Peripheral vascular disease & $440-444$ & I70-I74, I77 \\
Hyperlipidemia & - & E78 \\
History of cancer & $200-208$ & C \\
Myocardial infarction & 410 & I210-I214, I219 \\
NSTEMI & $410 B$ & I214 \\
STEMI & $410 \mathrm{~A}$ & I210-I213 \\
Stroke & - & I61-I64, I69 \\
\hline
\end{tabular}

ICD, International Classification of Disease; NSTEMI, non-ST Elevation Myocardial Infarction; STEMI, ST-Elevation Myocardial Infarction.

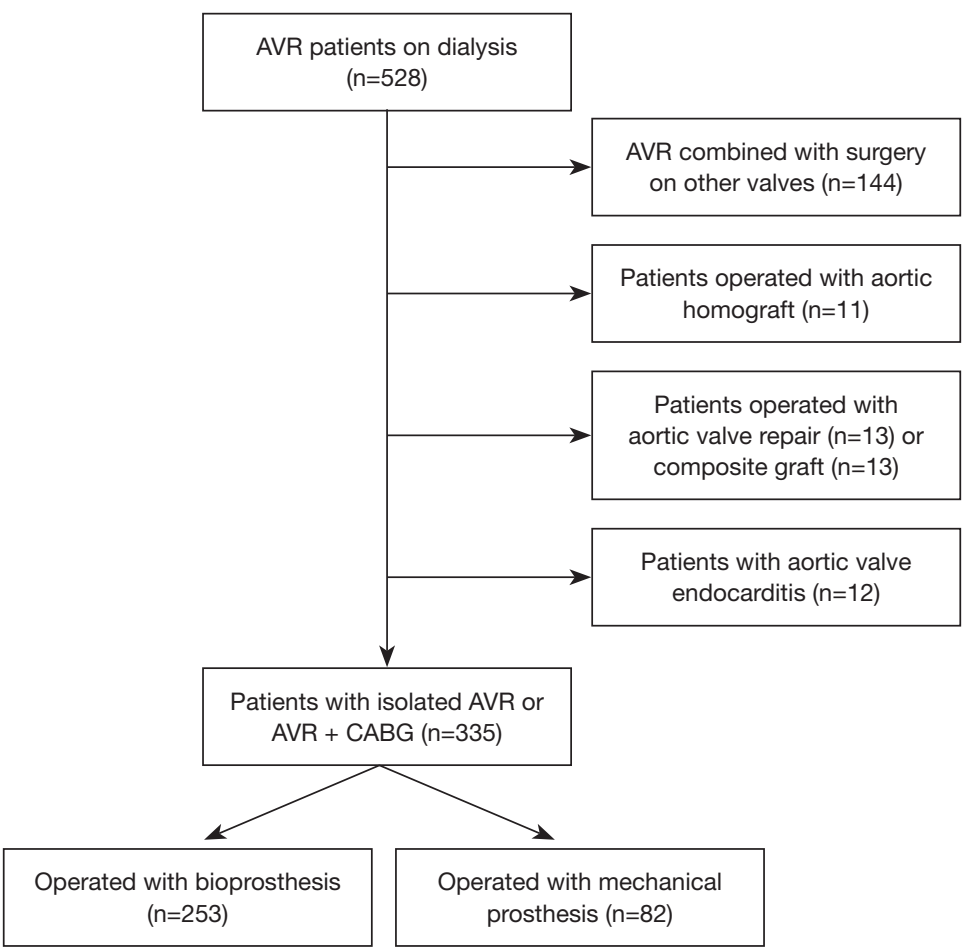

Figure S1 Flow-chart over included and excluded patients. AVR, aortic valve replacement; CABG, coronary artery bypass grafting. 
Table S2 Preoperative patient's characteristics in 335 dialysis patients that underwent aortic valve replacement with or without concomitant CABG

\begin{tabular}{|c|c|c|c|c|}
\hline Variables & Total population $(\mathrm{n}=335)$ & $\operatorname{AVR}(n=260)$ & AVR + CABG $(n=75)$ & $P$ value \\
\hline Age (years) & $67.1 \pm 10.5$ & $65.8 \pm 10.6$ & $71.5 \pm 8.7$ & $<0.001$ \\
\hline Body mass index & $27.0 \pm 5.2$ & $26.8 \pm 5.3$ & $27.8 \pm 4.7$ & 0.16 \\
\hline Logistic Euroscore (\%) & $8.3 \pm 4.26$ & $8.0 \pm 4.2$ & $9.3 \pm 4.2$ & 0.016 \\
\hline Previous stroke & $31(9.3 \%)$ & $29(11.2 \%)$ & $2(2.7 \%)$ & 0.030 \\
\hline Diabetes & $114(34 \%)$ & $77(29.6 \%)$ & $37(49.3 \%)$ & 0.003 \\
\hline Hypertension & $241(71.9 \%)$ & $182(70 \%)$ & $59(78.7 \%)$ & 0.18 \\
\hline Heart failure & $125(37.3 \%)$ & $88(33.8 \%)$ & $37(49.3 \%)$ & 0.022 \\
\hline History of cancer & $70(20.9 \%)$ & $57(21.9 \%)$ & $13(17.3 \%)$ & 0.49 \\
\hline Hyperlipidemia & $69(20.6 \%)$ & $43(16.5 \%)$ & $26(34.7 \%)$ & 0.002 \\
\hline
\end{tabular}

Mean \pm standard deviation or numbers and percentages. AVR, aortic valve replacement; CABG, coronary artery bypass grafting.

Table S3 Early complications in 335 dialysis patients that underwent aortic valve replacement with or without concomitant CABG

\begin{tabular}{|c|c|c|c|c|}
\hline Variables & Total population $(n=335)$ & $\operatorname{AVR}(n=260)$ & $A V R+C A B G(n=75)$ & $P$ value \\
\hline Reoperation for bleeding & $53(15.8 \%)$ & $45(17.3 \%)$ & $8(10.6 \%)$ & 0.17 \\
\hline Postoperative heart failure & $44(13.1 \%)$ & $29(11.1 \%)$ & $15(20 \%)$ & 0.046 \\
\hline Perioperative stroke & $36(10.7 \%)$ & $26(10 \%)$ & $10(13.3 \%)$ & 0.41 \\
\hline
\end{tabular}

Number and percentage. AVR, aortic valve replacement; CABG, coronary artery bypass grafting.

Table S4 Early postoperative complications in the propensity score matched population

\begin{tabular}{|c|c|c|c|c|}
\hline Variables & Total population $(n=130)$ & Mechanical valve $(\mathrm{N}=60)$ & Biological valve $(\mathrm{N}=70)$ & $P$ value \\
\hline Reoperation for bleeding & $3(2.3 \%)$ & 0 & $3(4.2 \%)$ & 0.25 \\
\hline Postoperative heart failure & $21(16.1 \%)$ & $7(11.6 \%)$ & $14(20 \%)$ & 0.24 \\
\hline Perioperative stroke & $5(3.8 \%)$ & $2(3.3 \%)$ & $3(4.2 \%)$ & 1.0 \\
\hline
\end{tabular}


Table S5 Demographics and patient characteristics of matched groups

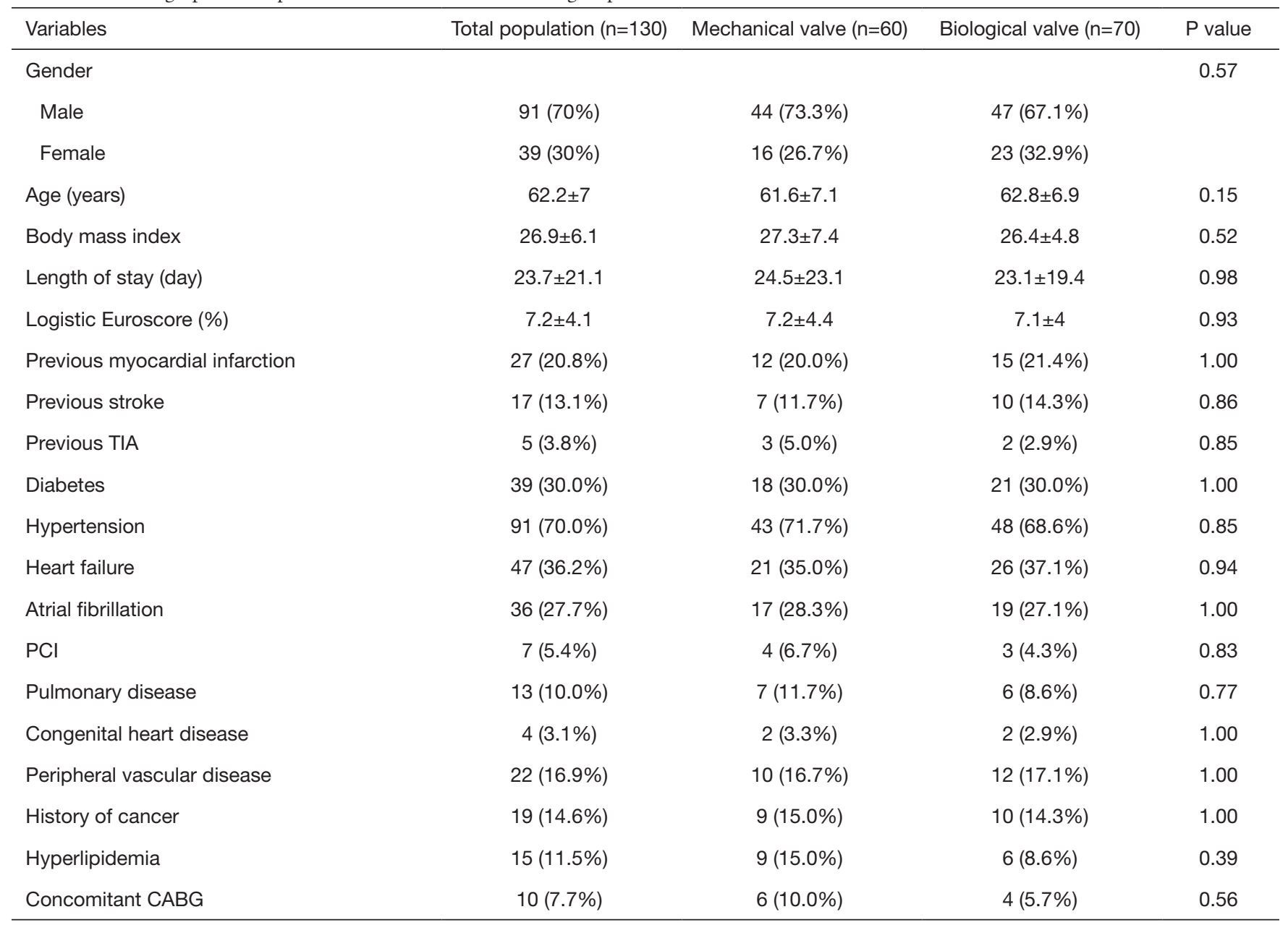

TIA, transient ischemic attack; PCl, percutaneous coronary intervention; CABG, coronary artery bypass grafting.

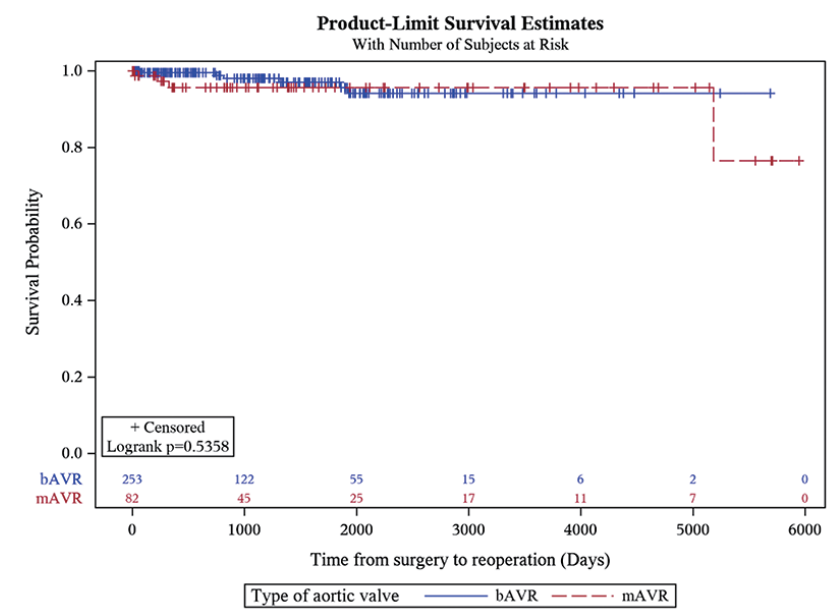

Figure S2 Kaplan-Meier analysis of aortic valve reoperations in the bAVR and the mAVR groups. bAVR, biological aortic valve replacement; mAVR, mechanical aortic valve replacement. 